\title{
OPEN
}

\section{7 \\ Feeling Fuzzy: The Emotional Life of Interdisciplinary Collaboration}

\begin{abstract}
Interdisciplinary collaboration is frequently considered hard intellectual and methodological labour. And it is that. But interdisciplinary work is emotional work too - and is riven by the presence of (and requirement to manage) many different kinds of feelings, not all of them joyful. This chapter takes up the analysis of emotion in interdisciplinary spaces arguing that such spaces are deeply dependent on forms of emotional regulation. The chapter works through moments, from our own work, in which we have felt bad, confused, and irritated. Thinking through how we managed these moments, the chapter positions interdisciplinarity as an affectively fuzzy domain, and much of the work of collaboration as learning to live though that fuzz. The chapter is appended with an epilogue to the broader monograph, which focuses on the two authors' own form of collaborative labour.
\end{abstract}

Keywords: affect; collaboration; emotion; emotional labour; emotional regulation; interdisciplinarity

Callard, Felicity and Des Fitzgerald. Rethinking Interdisciplinarity across the Social Sciences and Neurosciences. Basingstoke: Palgrave Macmillan, 2015. DOI: $10.1057 / 9781137407962.0010$. 


\section{Quit your whining!}

We are both participants in a carefully choreographed space that has been designed to elicit productive cross-disciplinary engagements between humanities scholars, life scientists, mind scientists, social scientists, artists, and engineers. The convenor uses the technique called 'open space', where a number of participants suggest topics for a discussion, and then each goes off somewhere and leads that discussion herself, with whomever else wants to participate.

Des suggests, to the larger group, the topic of 'emotional labour in interdisciplinary spaces': he wants to talk through some of the ways in which emotions (including disappointment, irritation, anxiety, upset, even the occasional bout of pleasure) press on, and thus shape, interdisciplinary spaces and research. There is a skipped beat - silence occupies the room for a short while, before several delegates (including the convenor, herself, who, by dint of her role qua convenor, certainly knows about emotional labour) gather to join Des.

One of our collaborators overhears someone nearby, from a discipline totally different from either of ours, say to her neighbour something along the lines of: "You go and have that session on emotions and emotional labour. But also, how about we quit whining and run a session on actually doing some work?"

This person was, of course, kidding. But her remark, like all the best putdowns, provoked us to think through something important: sure, it can be a relief to get your resentments and disappointments off your chest, but what do emotional labour, and reflections on that labour, have to do with 'actual work'? Why is it not simply whining? Leaving aside our suspicion that whining might, in fact, be an under-valued and understudied genre, this chapter is an attempt to answer that question. We argue, here, that not only is emotion work heavily implicated in research work, but the labour of interdisciplinarity is emotional in ways that depart from the regular affective challenges that accompany all collaborative endeavours. We are convinced that understanding interdisciplinarity in practice means understanding how, why, and with what consequences, interdisciplinary research spaces are underscored by thick, deep currents of often subsumed, and yet profoundly felt, emotion - whose sources and objects are often difficult to discern. And yet they can, when attended to, tell us a great deal about points of epistemological, ontological and political blockage within any interdisciplinary configuration. Those blockages, in turn, help us to understand which kinds of interdisciplinary crossings and exchanges are more or less possible or likely within that 
configuration - and hence why certain research questions, approaches and methodologies find fertile ground, while others sometimes run into the sand. In other words, emotional dynamics can have great power in enabling and closing down the pursuit of particular interdisciplinary research trajectories. To treat the emotional economy of interdisciplinary collaborative work as epiphenomenal to - rather than a significant shaper of - those cross-disciplinary research trajectories would be a mistake.

A second claim follows from such a diagnosis: collaborative work - and especially interdisciplinary work of the kind that we discuss in this book - is inseparable from particular forms of, methods for, strategies around, and investments in, emotional regulation. We have become convinced, in the course of the years that we have spent in these spaces, that when collaborators from very different disciplines work together, most of them depend significantly upon practices of emotional regulation. Such practices help to ensure that interdisciplinary collaborations do not fall apart, and are able - oftentimes - to result in collaboratively produced research. Notably, instances of emotional dysregulation can be startling indicators of moments at which regulatory practices have broken down; or of collaborators' deliberate calling of attention to the affectively freighted landscape in which they all are working; or of instances of interdisciplinary contestation that - for whatever reason - cannot be quickly subsumed back into the usual affective economy that characterizes any given interdisciplinary space. And when we think of this affective economy, we include not only researchers from all disciplines, but those such as project co-ordinators, convenors and facilitators. Their material and immaterial labour is indispensable in allowing interdisciplinary projects to get off the ground and to persist, though it is often invisible precisely because such labour threatens to be regarded as mere 'infrastructure'. (How gender - and gendered assumptions - work here is particularly important to attend to.) We want the chapter to illustrate how typical - and often banal - such feelings are. But we also want to use these affectively marked instances, and our analyses of them, to intervene in existing debates about what interdisciplinarity is like, and why it is often difficult to accomplish.

\section{Affects and their regulation}

There are two major theoretical preoccupations at the heart of this chapter. The first centres on why it is not enough to focus on epistemological 
differences between disciplines to understand the complications of interdisciplinary spaces. On our account, it is often difficult to determine the origin, quality, and after-effects of interdisciplinary moments of pique, disorientation, and friction. Such states work, frequently, to confound any possibility of speaking out or acting clearly and decisively (i.e. acting in straightforwardly agentic or political ways) in response to them. When the source of an emotion is unclear (as it frequently is with feelings of irritation or slight malaise or embarrassment), what is produced is often a sense of affective confusion or bewilderment - one that is very distinct from emotions with a clear origin and a distinct object (such as fury against a particular individual or a particular theory she holds). Such bewilderment does not necessarily lessen through a process of epistemological resolution. We are not simply describing, here, interdisciplinary situations in which a researcher feels confused because she does not have the knowledge base to understand the content of a collaborator's communication. Interdisciplinary spaces cannot be summed up, in other words, as spaces characterized by the movement from epistemological confusion to reasoned - or at least momentary - clarity, in which researchers manage to overcome their initial epistemic differences and build shared knowledge together.

We linger over this point since it is so commonly the orienting framework used to understand interdisciplinary spaces. (Much of the existing literature on interdisciplinary teams, for example, focuses on how researchers with different epistemic commitments 'share and integrate their cognitive resources in order to produce new results that cut across disciplinary boundaries' (Andersen and Wagenknecht 2012, 1881).) Sianne Ngai, in her work on 'minor and generally unprestigious feelings', distinguishes feeling 'vaguely "unsettled" or "confused", as an 'affective sense of bewilderment', from confusion that results from 'the epistemological sense of indeterminacy': such bewilderment - 'this feeling of confusion about what one is feeling' - might well, she suggests, be 'an affective state in its own right' (Ngai 2005, 14; italics in original). Our conjecture is that such kinds of 'affective disorientation' - to use Ngai's potent phrase - or of 'feeling fuzzy' (to use our own coinage) have been particularly common in the interdisciplinary spaces that we have inhabited. One of the purposes of this chapter is to begin to do justice to the important roles that these often ill-understood and often ignored affective states play in shaping the topologies and logics of interdisciplinary research. 
We realize that complex emotions are central to many, if not all, forms of practice - whether research based or otherwise. Historians of science and of emotion have compellingly demonstrated how potent scientists' affective responses have been in the generation of scientific models, concepts and data - whether we are talking about scientists' reactions in the face of animals' emotions, Darwin's flinching, or early theories of artificial intelligence (Dror 2011; Smith 2014; Wilson 2009). There is a growing body of sociological literature on how emotions move and coalesce within research laboratories (Fitzgerald 2013; Kerr and Garforth 2015). But there is something distinct, we feel, about the contours of affect that have moved and passed through us in profoundly interdisciplinary (as opposed to more mono- or multi-disciplinary) spaces. Here, the methods that researchers use can be so heterogeneous; the discursive conventions that make certain elements of the scene unsayable or sayable are so often not shared across disciplinary differences; the epistemologies can be so various; researchers' modes of bodily comportment so distinct from one another; and the settling on a shared object of investigation is, at times, impossible. The orienting ethos of an openness to alterity (the alterity of others' methods, ontologies, and ways of 'doing' research) that tends to frame the normative horizons of interdisciplinary spaces (even if it often does not play out in practice) is also, we think, a terrain conducive to the emergence of the kinds of complex affective states (including bewilderment) that we are interested in here. Bodily, psychological, affective - as well as more straightforwardly 'epistemological' - fuzziness and friction are, we believe, not so prevalent in more straightforward mono-disciplinary spaces (where researchers often have some sense of shared modes of conversing and comporting themselves, even if they profoundly disagree with one another), or multi-disciplinary spaces (where there is more commonly a shared sense that no one is really expected to open herself to the other's methods or ontologies, and that each can return 'home' more or less unchanged by the encounter).

Second, there is value in recognizing the important role that the regulation - and dysregulation - of affective states plays as emotions pass between and through members of an interdisciplinary team, as well as through artefacts and technologies (email and other writing technologies can be particularly vexed sites) that are central to the workings of any interdisciplinary research project. By using the term 'regulation' we want to capture the various ways in which individuals' and groups' affective states might be modulated: we are interested in how mental processes, 
physiological processes, comportment, and gesture intertwine; we are especially interested in how the emergence of friction and fuzziness - as well as of more clearly contoured emotions - can easily produce, in turn, attempts to attenuate or sidestep such feelings and dispositions. This might be through consciously practised emotional 'regulation', or indeed, if those attempts fail, through states of individual and collective dysregulation. Dwelling at greater length on the routes that affective responses can and do take in interdisciplinary projects might thus provide some markers for the interdisciplinary researcher to find her way through such projects, while retaining (most of) her sanity.

This is not the first time that either of us has written on this topic. We have elsewhere published more formal pieces on the role of affect in the psychological and brain sciences, on feelings of awkwardness in one interdisciplinary project, on how 'affect' itself has often been the theoretical and empirical ground upon which scholars have sought to 'become interdisciplinary', and on the complex looping of blame (Callard et al. 2012b; Fitzgerald 2013; Fitzgerald et al. 2014a; Papoulias and Callard 2010). We draw on some of that work here. Additionally, and in line with our broader goals for this volume, we mine some of our own fairly mundane encounters in the interdisciplinary scene. We draw out small moments - of fuzziness and of other affective dispositions - from our own immersion in interdisciplinary projects and places, to show how we have come to see emotions as variously diagnostic of the situations in which we - and, indeed, some of our collaborators - have found ourselves.

\section{Telling lies}

In Chapter 2, we described the outline of an experiment on neuroscientific lie detection in which one of us (DF) was involved. Again, in brief, the basic intuition of this experiment was that if it is possible to intuit (from literary, historical, and sociological analysis) that untruth is not, in fact, a natural state that can be isolated to particular neurological functions, then what would happen if an experiment were conducted that induced participants to tell a particular kind of awkward truth in the brain scanner - a truth that would show brain activity broadly similar to that previously associated with the state of lying? Over three days, the collaborators tried to answer this question by recruiting a cohort of local choir singers, and formed them into two teams. They told the 
participants that this was an experiment in team evaluation, and that they were to compete against one another in a series of tasks. Participants were told that events would culminate in a sing-off, in front of a famous local choir director - and they would then have individually to rate one another's performance, while in the brain scanner. Crucially, they were told the accuracy of these ratings would go into the overall evaluation. Unbeknownst to the participants, each team contained two actors, who were given two simple instructions: be very likeable, and sing horribly. When the participants came in to be scanned, after a long day's singing and competing, they thought they were evaluating other team members at random - but of course they all had to evaluate the nice-but-talentless actors. The research team hypothesized that telling the truth about those actors, in the scanner, would be really awkward, and socially potent, and cognitively taxing - exactly the cognitive functions, in other words, often associated with telling lies.

If this is a generic example of how a social-literary intuition (truth is a contextual phenomenon) might be threaded through a neuroscientific method to produce - potentially - a new insight, there was also a significant amount of emotional regulation involved in its execution. Throughout the procedure, there was a great deal of ambivalence and awkwardness: several of the experimenters involved retained an anxiety about whether this experiment was a good thing to be involved in; collaborators sometimes worried about what, precisely, they were contributing to the project and what, on the other hand, they were getting from it; people were occasionally irritated with one another (see Fitzgerald et al. 2014a from which this account partly draws). In one memorable early meeting where the project was presented to the wider laboratory hosting it, the lab members (as scientists will) got really stuck in to the specifics of the experiment, making several of the other experimenters worry about what this actually had to do with them anymore. And all of this is added, one can be sure, to the normal affective potency of doing an ecological experiment (the excitement of seeing actors move, unrumbled, through the participants; the tension of revealing the truth), as well as the kinds of bodily and emotional regulation necessitated by keeping up the pretence of the 'game' - and keeping the truth from the participants throughout.

But most significantly, perhaps, from DF's perspective, what was at stake throughout the experiment was a particular kind of regulation which is to say, the collaborators tacitly practised a kind of internal 
management of their affective states vis-à-vis the project. DF would go so far as to say that the experiment worked out precisely because of the emotional regulation practised by the experimenters who were part of it. This was, on the one hand, an experiment that was pregnant with emotion (and in particular, with forms of awkwardness, taciturnity, sullenness, and so on). On the other hand, DF believes, from his own perspective, that the researchers, themselves, rarely addressed this with one another. While they kept up a lively critical dialogue, nonetheless, when researchers were frustrated with one another, they often kept it to themselves; when they thought the others were flat-out wrong, they sometimes swallowed it; when they felt as though they were being talked-down-to, they frequently let it go; most significantly, when they weren't sure whether this was a very good experiment, or whether it was especially something they wanted to be involved in, or whether it was ever going to work, and even if they cared either way, they of course thought and talked about it - but it also seemed to DF that they sometimes quelled these anxious, ambivalent feelings, or regulated them, and moved on.

This is what we intend to draw attention to when we talk about the importance of understanding and working with the manifold ways in which affects are modulated, inhibited, it and transformed in interdisciplinary research projects. When we invoke matters of affective regulation, we are not articulating a prim warning about the impropriety of emotional outbursts. Rather, we're pointing to how intensely affectively weighted interdisciplinary spaces often are, and, also, to the fact that attention to - and management of - that weight, might have a significant bearing on the success, or otherwise, of an interdisciplinary encounter.

\section{Playa hater}

'This room is filled with neuroscience playa haters.' Felicity overhears this comment made at a workshop that is assessing the current state of neuroscientific evidence and models. It features a very small number of neuroscientists, a large number of social scientists and humanities scholars; amongst them are several very outspoken critics of neuroscience.

The term 'playa hater' emerged in late 1990s rap to describe those who criticize the successful strivings of those (like rappers themselves) who 
'made it' within a system not designed for them. (See, in particular, The Notorious B.I.G.'s 'Playa Hater', in which he sang about the two kinds of people in the world, today: the 'players' and the 'playa haters') What is going on here? First, in the move from 1990s rap to this researcher's diagnosing of the fractious - though, let's face it, rarefied - space of an interdisciplinary workshop on neuroscience? Second, in our deciding to include this culturally and historically dense moment, one that invokes a specific linguistic terrain, often associated with a particular kind of black masculinity, and that then uses that terrain to complexify what regular commentary might simply have characterized as predictable cross-disciplinary critique of neuroscience on the part of the humanities and social sciences?

First, let us consider the sentence, 'This room is filled with neuroscience playa haters.' FC believes this to be a moment of diagnosis, in which there was the identification (correct, FC believes) of some sense of grievance and envy on the part of at least some of those in the social sciences and humanities; as well as of a disparity in power between the neurosciences (strong) and those enviously attacking it (the weaker humanities and social sciences); as well as of the strangeness of running a conference about neuroscientific evidence that was filled with so many people 'outside' of the field and that contained so few practising neuroscientists. The sentence, on the one hand, can be interpreted as a powerful means both to gesture to a recent transformation in disciplinary hierarchies (the neurosciences were thrust into the limelight at the same time as the humanities were feeling increasingly anxious about their status) and a means to install (not wholly ironically) anyone issuing the sentence close to the heart of interdisciplinary power. But there is more going on here, too. The term 'hater', as it has emerged in the last couple of decades, conveys a complex mesh of affects: the 'hater' not only is unable to be happy about the success of the person she or he is 'hating', but rather wants to undermine that person by attempting to expose her flaws or inadequacies. Here, then, is an acute analysis of the shape that critique of 'the neurosciences', on the part of humanities and social science scholars, can sometimes take. FC remembers the atmosphere in the workshop as, indeed, at times, hostile against 'neuroscience' - and hostile in a way that refused any real engagement with the heterogeneous methods or epistemologies of the neurosciences, and that was forcefully committed to trying to identify as many flaws in 'neuroscience' as possible. She surmised that the use of the term 'hater', to describe some 
of those in the room, diagnosed the often disavowed affective underpinnings of a particular kind of critique that imagines itself as conducted on affectively neutral, reasoned, and deliberative grounds. The sentence, FC thinks, also expresses some bafflement that the neuroscientists in the room had been subject to such affectively intense critique, given that they were precisely those who had chosen to engage, in sustained ways, with those from other disciplines in order to interrogate neuroscientific models and evidence. But the affective dynamics of the workshop did not, FC believes, hold open the possibility of recognizing these kinds of 'entangled' cross-disciplinary labours: instead, they lurched towards a bifurcated field of 'haters' and 'playas'.

This overheard sentence, then, which might well usually have been sloughed off as a casual interjection and one unimportant to the 'work' of interdisciplinarity, made clear to FC how any attempt to understand that work needs to attend to the fraught and deep affective channels that shape how individual researchers - and the arguments they make retreat, advance, exchange, and disengage with fields different from their own. The sentence achieved this through a bold and unexpected importation of popular culture - specifically via the use of a term that emerged in African-American hip hop to anatomize the changing economic and social hierarchies of the street and the music industry. We want to stress that, in our experience, it has not been uncommon for this kind of ironic, multi-modal word-play - an informal register that can carry irritation, acuity, grandiosity, and hurt more openly than that of frequently strangulated academic exchange - to be the means through which we ourselves, as well as others we have heard commenting on interdisciplinary scenes, bear witness to some of the most difficult elements of interdisciplinary working.

A quick postscript: The term 'playa hater' began to travel, sometimes invoked by us and by some of the people with whom we collaborate; it become a way to track interdisciplinary power dynamics. One of us (FC) has herself, on a number of occasions, been described, good-naturedly, as a 'neuroscience playa hater'. She certainly didn't easily identify with being one (not least given the unhappy analysis we have just provided above), and she certainly didn't see herself consciously wanting to endorse a bifurcated vision of the world in which there are simply the 'playas' and the 'playa haters'. She did, however, reluctantly have to acknowledge that she did recognize certain aspects of herself, as well as of the affectively fraught field of interdisciplinary research on the mind and brain, that 
the phrase 'playa hater' serves to conjure up. Let's face it, she'd felt the envy of the hater. In her potent analysis of 'ugly feelings', Sianne Ngai argues that 'envy lacks cultural recognition as a valid mode of publicly recognizing or responding to social disparities, even though it remains the only agonistic emotion defined as having a perceived inequality as its object' (Ngai 2005, 128). The temptation is always to tell the envious person to 'get over it' - where 'it' is a designator of the inadequacy of that individual's psyche - rather than to think through the imbrication of the psychological and the social so as to understand what it is that provokes the desire to inhabit (or to crush) the space of the other. It would be fair to say that FC hasn't 'got over it'; her envy is still strong. But the introduction - and then circulation - of the figure of the playa hater ended up, over time, having a significant effect on how she herself thought about, and indeed entered into, collaborations with those from other disciplines - as well as how she thought about the spatial logics of the interdisciplinary field in which she was a participant. The diagnostic precision of the phrase 'playa hater' perhaps allowed her, over time, to move from 'feeling fuzzy' about how such an appellation had ended up being attached to her, to being able to inhabit an interdisciplinary landscape that she was less likely to construe in such agonistic terms.

\section{Coming from the outside}

Here is another example, not only of the density of emotions in interdisciplinary spaces, but of the ability of emotions both to unseat those experiencing them, as well as to orient the grooves down which interdisciplinary research might go in the first place. This time, we focus on annoyance (see also Ngai 2005 on irritation). Some years ago, one of us (DF) applied for funding for a research project, in which he proposed among other things - to interview people with a neurodevelopmental diagnosis about prospects for treatment (which were then remote, but certainly under investigation). His project, although grounded in the social sciences, was intended to work, in an interdisciplinary manner, through a larger bioscientific research endeavour - and to offer to that project, in exchange for its imprimatur, a sense of how service users and their families thought through issues around biomedical intervention. In the event, he wasn't funded, and the project never got off the ground which is itself a banal and quotidian event. But what was interesting 
was how the project proposal was reviewed - and, in particular, how at least one reviewer, through what DF read as a sense of frustration and irritation, positioned the proposal as a poorly-conceived, attempted intervention from the outside. 'I was deeply disappointed by this project for several reasons', the reviewer began: '... the candidate appears to believe that scientists are on the verge of developing a possible biological therapeutic intervention... But this is simply not the case.' Indeed, DF's project in general 'display[ed] a shocking lack of familiarity with the state of biomedical science in this area.' Worse, the topic that he proposed to interview people about had 'no grounding in biomedical fact', while he had failed to 'familiarise himself with the literature' around the diagnosis in question. Indeed, his proposal 'illustrate[d] a degree of ignorance that is very disappointing', while his 'nonsensical framing' of his questions '("garbage in")' would only produce 'nonsensical data ("garbage out")'. "Coming to a topic from the "outside" can sometimes be highly valuable', the review concluded, 'but the demands of a topic such as this necessitate some understanding of the nature of [this diagnosis] and how it affects people and their families....

There is a great deal that might be said here. The reviewer refers to DF as an 'outsider' to 'the field'. They position him as someone who is not simply wrong but in fact 'ignorant'. They locate his questions outside of the zone of respectable sense-making, position his failure as an absence of preparation, wonder if he has faced up to the 'demands' of the scientific material, and so on. But let us draw two things out in particular: first, the territorial dynamic of inside and outside, of expert and candidate, of serious research and garbage, within which these remarks are couched. We are not quibbling, here, over whether or not this project should have been funded: fine projects exhaust the limit of available research funds every day, and indeed we are quite willing to accept that the project in question did at least exhibit some of the deficiencies described. But what remains pertinent is the series of bifurcations in which the review was nonetheless couched - and, moreover, the proposal seems to have been read as a (poor) attempt to intervene in a bioscientific space, from the outside. Being adjudicated on such grounds - rightly or otherwise - is certainly one feature of trying to lead an interdisciplinary life. But we want to note, second, how affectively charged this exchange, conducted via the transfer of written materials, seems. We refer, here, not only to DF's own sense of annoyance, embarrassment, and so on, at these remarks, but to the intensity of irritation that DF reads in the review. Perhaps, indeed, 
he over-reads. But the language of disappointment, concern, and shock appears, at least initially to him, as otiose: the reviewer, after all, could have elaborated why he or she found the proposal deeply problematic without these affective supports. We want to raise the question, then, as this chapter progresses, of what we might conclude about the contemporary landscape of interdisciplinary research if we pay close attention to the affective structure in which this exchange is suspended.

\section{Anti-political}

At the end of the lie detection study discussed above, one of us (DF) and his colleagues wrote a more formal auto-ethnographic account of how it felt to participate in a social science/neuroscience collaboration. In coming to understand their project, the authors set themselves against a recent, high-profile account of collaboration (between natural scientists and social scientists) gone wrong, by Paul Rabinow and Gaymon Bennett (Rabinow and Bennett 2012). Whereas Rabinow and Bennett had argued for rather more frank speaking in highly-charged interdisciplinary spaces, DF and his colleagues suggested, in deliberate contrast, that:

[our] success might have come precisely because we did not speak frankly; we did not seek the truth; we totally failed to acknowledge - let alone discuss the consequences of our experimental situation. What we did, instead, was to try to work and live within a zone that was just about ambiguous enough to keep everything together - that was sufficiently averse to frank-speaking to keep the worst of the resentments at bay. (Fitzgerald 2014a, 716)

That paper became part of a wider set of interventions in which DF and FC, both separately and together, had been trying to think beyond the usual encomia for truth and frankness. We focused, for example, on what it meant to become a 'subject of collaboration' - and we suggested that such a becoming might mean learning to find joy and insight within some more ambiguous and confusing ethical structures than those espoused by frank speakers of collaborative truth (Fitzgerald and Callard 2014). This last contribution, hosted on an interdisciplinary blog, produced (indeed, to be fair, literally invited) a response from a group of scholars, led by Anthony Stavrianakis, and including Rabinow and Bennett - the tone of which seemed, to us at least, somewhat irate. The 'determined self-limitation' described in our work marked, for these 
authors, 'a troubling turn in the practice of truth and ethics' - suggesting a moment, indeed, in which researchers seemed willing to give up on:

exercises of critical self-formation that prepare one to take up truth-practices in the face of shifting power relations and the attendant need to speak frankly about both power and the truth as one finds it. (Stavrianakis et al. 2014)

Worse, our espousal of the importance - and complexity - of play, over the need to seek clarity, was interpreted not as 'the uninhibited and spontaneous activity of scientific curiosity' (Stavrianakis et al. 2014), but, rather, as representing 'a species of ethically deformative bureaucratic administration' - one marked by (here the authors draw on Robert Merton and John Dewey) an "occupational psychosis"' in which abilities become blind spots, and one begins to internalize 'the limitation of one's authority and competence'. Collaboration conducted under such conditions, Stavrianakis and his colleagues argued, is determinedly 'antipolitical - and not in the scientific sense of seeking objectivity, but rather in the self-delimiting sense of turning away from the demands of the day' (Stavrianakis et al. 2014).

We were dismayed, on reading this text, to find our investment in the multiplication of ethical repertoires in the present, and our attention to the possible insights of play, to be subject to a rebuke that seemed so committed to analyses of function and bureaucracy, of truth and ethics, of art and critique, as these had been elaborated in mid-century (masculine) social theory. Might it not have not occurred to us - within our self-reported confusion - that complex questions of ethics, justice, and practice were at stake? Worse, the 'agonistic friendliness' espoused by Stavrianakis and his colleagues, as a counterpoint to our enjoinment to play, seems only to reassert a rather obvious starting position, wrapped in a (surely) unsustainable model of collaborative subjectivity. In either event, it has nothing to say with regard to the object we are trying to understand, viz. the ethical and affective nuance of collaboration in practice. But what interests us more than these intellectual disagreements is the sense of - and here we are frank - patrician touchiness through which this rebuke took shape. When we talk about the need for emotional regulation in interdisciplinary spaces, we are referring to the requirement for the interdisciplinary researcher to habituate herself to such registers of critique - and not just stoically to withstand such a reproach, but to attempt to quell her own heartfelt desire to respond, in kind, in 
her turn. The question that we have had, continually, to ask ourselves is: how are we going to make research happen, when the desire for (and our practice of) interdisciplinarity has introduced a state of such conceptual and normative suspension, that we find ourselves surrounded by colleagues who variously understand our work to be garbage, or see us as ethically deformed bureaucrats?

\section{The feeling of what doesn't happen}

This book disturbs the tendency, in writings about interdisciplinarity, to cleave to the terrain of ideas, disagreements, and knowledge claims - and, in so doing, to disavow the complex ripples, wrinkles, and patternings of affect that course through what is all-too-often assumed to be an unruffled plane of interdisciplinary interaction. We pay attention, here, to how those wrinkles get rubbed out, how they are sometimes smoothed over, and how, sometimes, they endure within and between the unsuspecting bodies of interdisciplinary researchers themselves. We have tried in this chapter to bring to visibility some of the political, methodological, ontological, and epistemological work that those emotions perform. We hope to have shown: (1) how emotion can be influential in carving out the perimeters of an interdisciplinary space (as well as determining who is inside and outside of it); (2) how researchers can engage in various tactics to ensure that collaboration does not entirely fall apart; (3) how political and ontological differences can be experienced affectively (and vice versa); (4) how the eruption of unexpected - and superficially unimportant - moments of affect can be diagnostic of important lines of conjunction and contestation within interdisciplinary spaces; and (5) how acknowledgement of affective bewilderment while in interdisciplinary spaces is easily misconstrued as either a deliberate or unwitting removal from the terrain of the political.

We worry that our inclusion of instances of mostly negatively valenced emotion has been done, at least in part, through some desire to seek sympathy, to settle scores, or to parade, in the interests of exhibitionism, shameful episodes of our own making. But we also want to insist that to decide not to attend to the movements and textures of, and manifold responses (whether regulatory or dysregulatory) to such emotion in interdisciplinary spaces, is to miss much of what is happening in them. If the would-be collaborator hears a strong note of caution - even 
warning - in this chapter, she has not misinterpreted our intent. We really do want these incidents - minor and anecdotal as all of them are - to begin a conversation about the range, shape, and effects of such intersectional and affective moments within interdisciplinary spaces, and how those moments might be encountered.

We have drawn particular attention to emotional regulation not only to attend to modes of self-management that the interdisciplinary researcher is called to (although we take these very seriously). Focusing on 'regulation' has also been a way for us to think against the grain of mastery and frankness in the interdisciplinary scene; it has, in particular, helped us to move beyond the stentorian banalities of 'truth' and 'power' in writings on collaboration - and thereby to think about how interdisciplinary life might be lived through less conventional ethical and philosophical practices. Most importantly, turning to the metaphor (although it is not only a metaphor) of regulation has helped us to understand much better what is going in the empirical projects that have captured our (interdisciplinary) attention. There is, for example, no cut between the subject of our lie-detection experiment, wondering how or whether to tell awkward but necessary truths, and the experimenters themselves, constantly unsure about how they might (if they might at all) voice their own anxieties about the experiment. What we have called in this chapter 'feeling fuzzy', and the affectively precarious responses that the interdisciplinary researcher makes in the face of this destabilizing bodily and mental state - is not incidental to the kinds of precarious, awkward, ambiguous, anxiety-inducing topics with which she is precisely trying to get her hands dirty.

\section{Notes \& Queries: 7}

Q: I worry about tensions and emotions in my interdisciplinary workwhat advice do you have for dealing with these?

A: Our answer is going to sound like advice that is appropriate to any group of people working collaboratively together: how do temperament and discipline combine and diverge within and across individuals? How might one regard an eruption of affect - or the collection of affect around a particular person - as diagnostic of some of the things that are going on in and across the wider collaboration? Tracking a group's interdisciplinary processes, here, might 
be helpful - so as to bring to the surface how different and difficult these modes of working can be. There are bound to be rough spots in any such collaboration, and allowing all to acknowledge this might open up ways for things to move forward. It might also be helpful to acknowledge - across all members of the collaborative group - how psychologically, practically, and emotionally exhausting interdisciplinarity can be.

But perhaps it is worth staying with this feeling, rather than always labouring with the assumption that things need to be addressed or resolved (whether immediately or across the longer term). This is not to say that one cannot - or indeed, should not - speak up when experiencing this kind of exhaustion, or when otherwise pinioned by negative affect. Of course, sometimes relations are just uninterestingly bad, and people positioned in ways that are unacceptable: we do not advise, in such situations, simply to get over it, or to stay quiet. But what we are trying to say is: the affective weight of an interdisciplinary collaboration may be as much a datum to be considered as a situation to be managed. We have learnt so much about our own collaborations from such an attention - insight that would have been quite lost by insisting on, for example, clearing the air. The question then is: what might be learnt from the tensions and emotions that run through a particular project? What do they reveal about the broader intellectual and psychological structure in which the project is caught? What can they tell us about how interdisciplinary knowledge is produced? Might they ultimately help us - if, indeed, it is progress that we are after - to pin down the broader pressure points, and anxieties, and aches, that are ultimately blocking that progress?

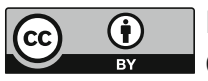

Except where otherwise noted, this work is licensed under a Creative Commons Attribution 3.0 Unported License. To view a copy of this license, visit https://creativecommons.org/licenses/by/3.0/ 